Grand. The appearance of this "distributor" is very much like a miniature cart-wheel, about five incoes in diameter, inclosed in a circular glass-case, the spokes being the twelve contact springs and the nave a small insulated table which, when the standard automatically closes the contact springs of the time-wire at the exact sixtieth second every hour, is instantly carried down upon and closes the twelve pair of contact-springs connecting the twelve line-wires with their batteries.

Many interesting methods have been adopted for testing and other purposes of maintenance, but we have only space to mention two. One is for the purpose of warning in case of a break-down. This consists of an ordinary electric clattering bell, with a small clock attached, and also connected with the line-wire. So long as the timecurrents pass regularly through this instrument the alarmbell remains silent; but five minutes after the failure of any time signal to pass out upon its duty, the alarm-bell begins to ring violently, continuing to do so for five minutes, and then leaving a small drop indicator, showing on which line the break-down has occurred. There is only one alarm-bell, but each line requires its attendant little timepiece (which, being "synchronised" by the passing current, never can be wrong) and drop indicator. The other instrument is an alarum answering the following important purpose :-A break-down being reported, a plug is placed in a "bridge" corresponding to the number of the line, which causes a very weak current (too weak to affect any of the synchronisers) to pass out along the line for the use of the linesman when searching for the fault; this found and repaired it is important that the plug should be immediately removed : to call attention at the office in Cornhill the linesman has only to break contact at the nearest clock anywhere on the line to set the alarum going in the instrument room, when, the plug being removed, the alarum is shunted off and the line clear for work.

We now come to the chief specialty of the system of Messrs. Barraud and Lund, namely, the synchroniser. This is an automatic finger-and-thumb action, brought to bear hourly on the minute-band, and bringing it, whether fast or slow, "to time." Each synchroniser is complete in itself, and is simply screwed behind the dial of the clocks to be synchronised. It is as follows :-

Two levers carrying pins, and representing the human finger and thumb, project through a slot in the dial (Fig. I), and either, close upon the end of the minute hand itself, or upon a small block fastened to it underneath; the two levers have at their other end slots in which two pins work, projecting from the leeper of an electro-magnet, which, when magnetised at the given moment by the closing of the contact springs on the standard clock, draws the pins together, and sets the hand to time. A reference to Figs. 2 and 3 will at once make the modus operandi clear. $\mathrm{E}$ is an ordinary electro-magnet, $\mathrm{G}$ the keeper, carrying a bar, $\mathrm{H}$, and two projecting pins, $\mathrm{K} \mathrm{K}$; these act in slots $L L$ in the levers $M M$, from the ends of which project the pins oo (representing the human finger and thumb); the passage of the current draws down the keeper and bar, acts upon the levers $M M$, closing them upon the minute hand of the clock and setting it, whether fast or slow, to time.

The following are some of the special advantages claimed for this system :- . That any number of clocks, few or many, of any varying sizes, can be synchronised to any agreed standard time-keeper. 2. That the mechanism is, when not in its momentary use, entirely detached from the works of the clock. 3. That it can be applied to existing clocks by simply being screwed in its place, and a narrow slit cut in the dial. 4. That any failure in the transmission of the time-current leaves the clock going in the ordinary way, to be "set to time" by the next completed current. 5. That the clocks are kept to time, whether having otherwise either a gaining or losing rate, even if such rate amounts to many minutes a day.

It will seen from the above description that the system owes its success not to the discovery or application of any new fact, such as that for which such eager search is now being made to secure a perfect electric light, but from the simplicity and efficiency of the synchronisers, and their adaptability to every kind and size of clock. By the simple expedient of winding the coils of all the instruments with one size wire, any number, all of varying sizes and powers, can be connected up in circuit. In the City circuit alone, which is wholly controlled by the standard at 4I, Cornhill, Io8 clocks on eleven different lines of an aggregate length of ten miles, and connecting over eighty different establishments, are efficiently kept to true time. Many more, we believe, are kept to time, not only in other widely distant parts of London, but in various parts of the country; for the latter purpose Messrs. Barraud and Lund have a contract with the Postal Telegraph Department for the delivery of time currents at certain hours each day. There is now no reason why all our public clocks at least should not be included within the correcting power of this system, and lead us astray no longer.

\section{THE TELEPHONE, ITS HISTORY AND ITS RECENT IMPROVEMENTS ${ }^{1}$}

\section{III.}

\section{The Carbon Telephone}

I $N$ the columns of this journal (NATURE, vol. xvii. p. 5i2) the present writer remarked in the early part of the year "that it was unlikely the telephone of the future would employ the voice to generate the driving power, as it does in the magneto-telephone, but only to modulate the flow of a current obtained by coarser means. It is in this direction that Mr. Edison is working, and his practical triumphs in the past are the earnest of success to those excellent telephonic investigations wherein he has already won an enduring fame." Since those words were written Mr. Edison has brought his telephonic experiments to so successful an issue that his carbon transmitter and his new receiver leave little to be desired in electric telephony, except the automatic record of the received speech, and this, it is not impossible, may ere long be accomplished.

The object Mr. Edison sought to attain was a variation in the resistance of the circuit proportional to the motions of the vibrating diaphragm of the transmitter. Gray employed for this purpose a liquid resistance, but owing to the fact that all suitable liquids are decomposed by the current, Edison abandoned them and tried solid conductors. He remarks in Prescott's work on the telephone:-

"In the spring of 1876 , and during the ensuing summer, I endeavoured to utilise the great resistance of thin films of plumbago and white Arkansas oil-stone, on ground glass, and it was here that I first succeeded in conveying over wires many articulated sentences."

A spring attached to the vibrating diaphragn was arranged so as to cut in and out of the circuit more or less of the plumbago film. But the results were not very favourable. In January, I877, a new device occurred to Edison, namely, the employment of a peculiar property which semi-conductors have, of varying their resistance under pressure. ${ }^{l}$ For this purpose

\footnotetext{
Continued from p. 14

${ }^{2}$ We have already considered in a previous article the historical facts connected with this discovery, and therefore it will be needless to refer to this point here. A reference to the Journal Télégraphique of Berne for 1874 , wherein it was asserted M. Clérac had anticipated the use $\mathbf{M r}$. Edison has made of the varying resistance of carbon dust under varying pressures, fully confirms the statement we made in our last article that the merit of this due to M. Clérac at all, who simply used permanently conpressed carbon dinst as a rheostat.
} 
the diaphragm was made to press against a little cylinder of crude plumbago. The articulation was poor, though conversation could be understood. Investigation showed that the difference of resistance produced by varying pressure was exceedingly small. As so small a change in a circuit of large resistance was but a small factor, whereas a slight change of resistance in the primary circuit of an induction-coil would be an important factor, it occurred to Edison to associate an induction-coil with his arrangement. But difficulties arose from the high resistance of the plumbago cylinder he first used. Ultimately he constructed a transmitter in which a thin slice or button of a semi-conducting substance was placed between two platinum discs. Electrical connection between the button and discs was maintained by the slight pressure of a piece of rubber tubing which was secured to the diaphragm, and also made to rest against the outside disc. The vibrations of the diaphragm were thus able to produce the requisite variations of pressure on the button and thereby create corresponding variations in the resistance in the primary circuit of the induction coil; which in turn gave rise to a corresponding series of induced currents in the secondary. Finally, these induced currents were transmitted through the line and received at the far end by an ordinary magnetotelephone. Fig. I, for which we are indebted to the Telegraphic Journal, shows the arrangement.

At first a button of solid plumbago, such as is employed by electrotypers, was used, and the results obtained were considered excellent, everything transmitted coming out moderately distinct, but the volume of sound was no greater than in that of the magneto-telephone. $\mathrm{Nu}$ merous other semi-conductors were tried until Edison hit upon some lamp-black that had been taken from a smoking petroleum lamp and preserved as a curiosity on account of its intense black colour. A small disc was made of this substance, and when placed in the telephone it gave splendid results, the articulation being distinct, and the volume of sound several times greater than with a pair of telephones worked on the magneto principle. It was soon found upon investigation that the resistance of a disc formed of this substance could be varied from $300 \mathrm{obms}$ to the fractional part of a single ohm by pressure alone, ${ }^{1}$ and that the best results were obtained when the resistance of the primary coil, in which the carbon disc was included, was six-tenths of an ohm, and the normal resistance of the disc itself three ohms.

The rubber tube between the diaphragm and the disc gave some trouble on account of its tendency to become flattened. Experiments undertaken with a view to remedy this defect led Edison to discover that not only could a rigid substance be interposed with advantage, but that the vibrating diaphragm even was unnecessary; that, in fact, the sound-waves could be transformed into electrical pulsations without the movement of any intervening mechanism. Edison states that the manner in which he arrived at this result was as follows:-

"I first substituted a spiral spring of about a quarterinch in length, containing four turns of wire, for the aubber tube which connected the diaphragm with the discs. I found, however, that this spring gave out a musical tone which interfered somewhat with the effects produced by the voice; but, in the hope of overcoming this defect, I kept on substituting spiral springs of thicker wire, and as $I$ did so $I$ found that the articulation became both clearer and louder. At last I substituted a solid substance for the springs that had gradually been made more and more inelastic, and then I obtained very marked improvements in the results. It then occurred to me that the whole question was one of pressure only, and that it was not necessary that the diaphragm should

'The present writer can confirm this statement, but everything depends on the exact quality of the lampblack, the least trace of overheating lessens its intense blackness and enormously dimin:shes its conductivity. vibrate at all. I consequently put in a beavy diaphragm, one-and-three-quarter inch in diameter and one-sixteenth inch thick, and fastened the carbon disc and plate tightly together, so that the latter showed no vibration with the loudest tones. Upon testing it I found my surmises verified: the articulation was perfect, and the rolume of sound so great that conversation carried on in a whisper three feet from the telephone was clearly heard and understood at the other end of the line.'

The present and modified form of the instrument is shown in the next diagram, where $A A$ is the thick iron diaphragm, $\mathrm{B}$ the rigid connecting-piece pressing together the metal discs D D and the carbon disc $C$. The pressure can be regulated by the screw $\mathrm{S}$ acting upon the sliding stem $\mathrm{E}$, which terminates in an insulating cup that encloses the carbon and metal discs. Wires lead from $D D$ to binding screws.

It has been urged that Edison was led to adopt this arrangement by the discovery of the microphone, it is therefore of historical interest to note that in the American Journal of the Telegraph for April 16, 1878, it is stated "In the latest form of transmitter which Mr. Edison has introduced, the vibrating diaphragm is done away with altogether." A week or two later the discovery of the microphone was announced, and the transmission of speech without a vibrating diaphragm aroused universal surprise; the loose contacts which are essential to the microphone are, however, fatal for telephonic purposes.

It must be understood that the carbon telephone only acts as a transmitter; it is incapable of reconverting the electric pulsations into sonorous vibrations. For this purpose the ordinary magneto-telephone is employed. ${ }^{1}$ The accessories and electrical connections requisite for use in a carbon telephone circuit are shown in the next diagram (Fig. 3).

$P$ P is the primary wire of an induction coil having a resistance of several ohms and placed outside instead of, as is usual, inside the secondary coil $s$, which has a resistance of some $200 \mathrm{ohms}^{2}{ }^{2} \mathrm{R}$ is the receiving magnetotelephone and $\mathrm{T}$ the transmitting carbon telephone; either one or the other can be thrown into the circuit by means of the switch $\mathrm{K}$. When a plug is inserted at the bottom of the switch between 3 and 4 , the relay or sounder $S$, battery $\mathrm{B}$, and key in the centre of the figure, are included in the main line circuit. This is the normal arrangement of the apparatus for signalling purposes. To call the distant end the key is pressed down two or three times; by this means battery currents are sent through the primary coil $P$, the currents thus induced in the secondary coil $s$, pass to line, and actuate the relay or sounder in the distant instrument. When a plug is inserted at the top, between I, 2 , and 4 , the apparatus is available for telephonic communication. By tracing out the connections it will be seen that in this latter case the battery, $B$, the primary wire of the coil, $P$, and the transmitter, $T$, are in short circuit, and at the same time the line wire is in circuit with the secondary coil, s. A general view of the arrangement is shown in Fig. 3, for which we are indebted to the publishers of Count du Moncel's book on the telephone. The lettering is different, but the respective parts can be readily understood. In this case a polarised relay and electric call-bell are employed instead of the sounder, a necessary addition in long circuits.

Concerning the actual performance of the carbon tele-

I The use of the Bell telephone as a receiver in Edison's instrument is at present the subject of legal proceedings; Edison, however, claims to have used the maneto-receiver used the magneto-receiver before Bell invented it, and we learn that a letter has recently arrived from Mr. Edison stating that he has now constructed a still better and novel receiver for his telephone. Edison remarks: "Batchelor, cne of my assistants, heard a whisper last night fifteen feet away from the receiver, and ordinary conversation comes out as loud as originally spoken." Further information about this receiver is given at the close of this article. ${ }^{2}$ In the last improvements the usual position of the primary and secondary coils has been reverted to; the resistance of the former for short circuits should be about a third of an ohm and of the latter somewhat over seventy ohras. 
phone, it is stated in Prescott's work on the telephone that Mr. Bentley, President of the local telegraph company at Philadelphia, has succeeded in working with it over a wire of 720 miles in length, and has found it a

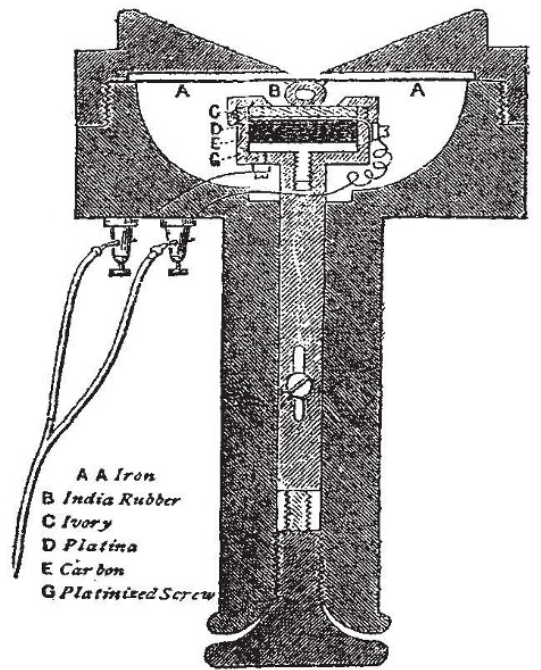

FIG. I.-Section of Carbon Telephone-Early form.

practicable instrument upon wires of 100 to 200 miles in length, notwithstanding the fact that the latter were placed upon poles with numerous other wires, which occasioned sufficiently powerful induced currents in them

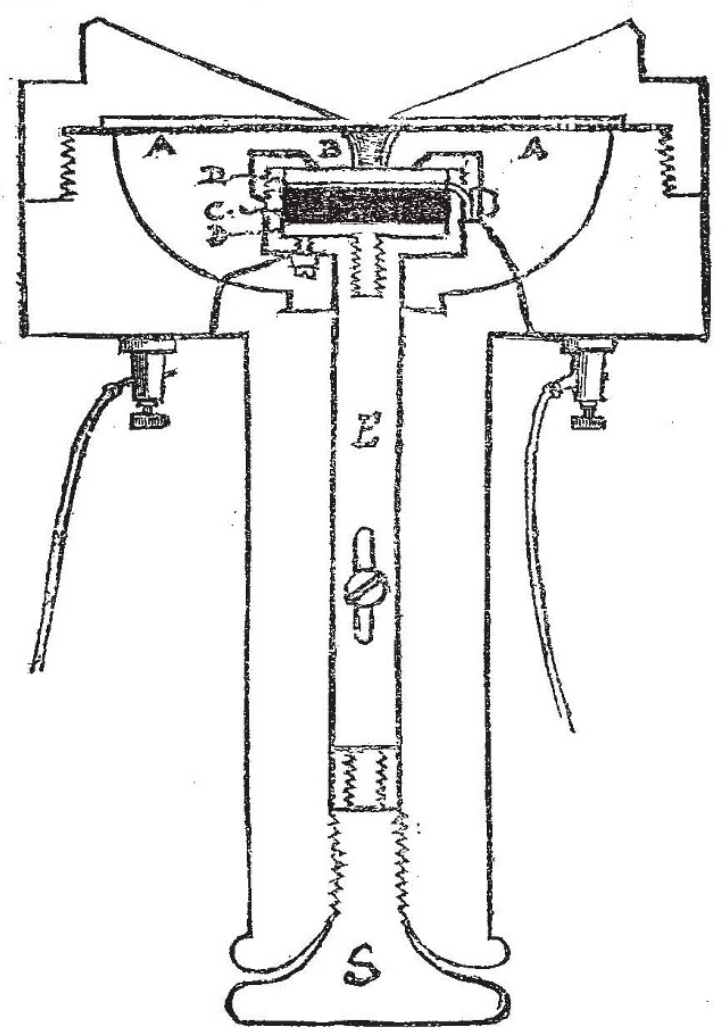

Fig. 2,-Section of Carbon Telephone--Latest furm.

to entirely destroy the articulation of the magneto-telephone. Further, he has found the instrument practicable "when included in a Morse circunt, with a battery and eight or ten stations, provided with the ordinary Morse apparatus ; and that several way stations could exchange business telephonically upon a wire which was being worked, quadruplex, without disturbing the latter, and notwithstanding, also, the action of the powerful reversed currents of the quadruplex on the diaphragnis of the receiver. It would thus seem as though the volume of sound produced by the voice with this apparatus more than compensated for the noise caused by such actions." Mr. Edison's assistant, Mr. Adams, now in England, states that conversation has been carried on during the night between New York and Chicago, places nearly 1,000 miles apart; and that under less favourable circumstances during the day the carbon telephone has been successfully used over a line of about half this length. Mr. Adams also informs the writer that at the Paris Exhibition he was able to transmit the music of a piano from Paris to Versailles, a distance of more than 20 miles; the piano standing 50 feet from the carbon telephone and yet not a note was lost at Versailles.

The present writer has had an opportunity of testing

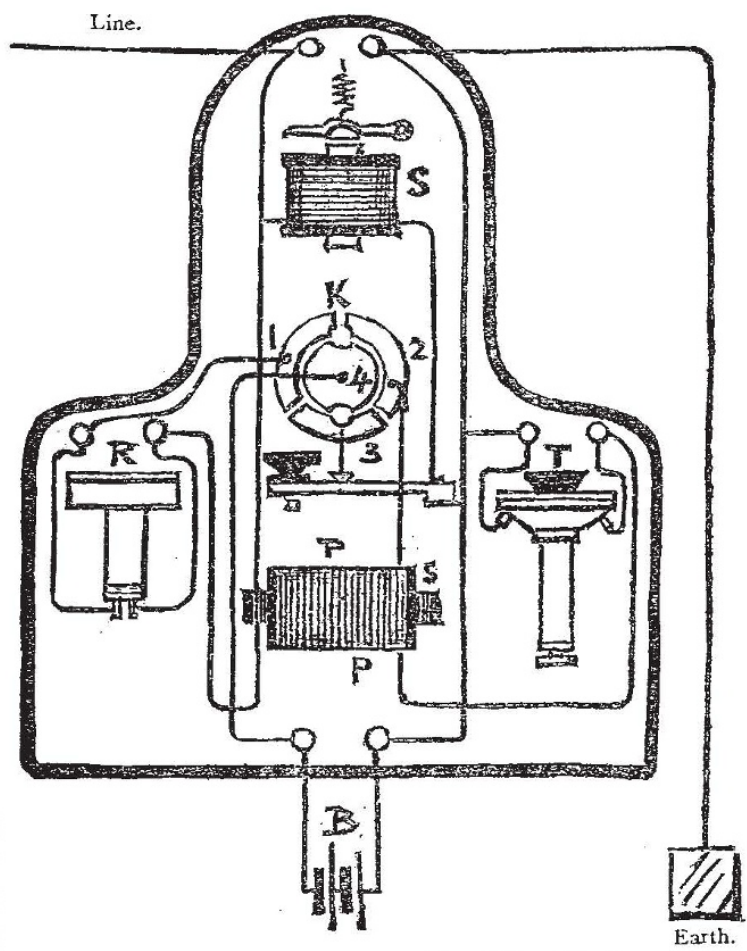

FIG. 3.-Electr:c arrangement of the Carb n Telephone.

this instrument in a recent lecture at the Midland Institute, Birmingham, and the surprising loudness of the tones received bas been noticed in NATURE. Words spoken some thirty feet from the transmitter were clearly heard in the distant receiver, whilst loud speaking close to the transmitter enabled more than a hundred persons to hear simultaneousiy the words spoken when a paper cone was added to the receiver. And furthermore, single exclamations, such as Bravo! could be heard by the whole of a crowded audience of upwards of a thousand people. Even when the line wire was broken, the fractured ends being near to, but not touching each other, conversation could still be carried on through the circuit with the carbon telephone, though communication by the magneto-telephone and the ordinary telegraphic instruments was entirely interrupted. The writer has also just: made further and more severe trials with this instrument on, he believes, the longest private wire in constant use in England, namely, that belonging to Messrs. Colman, 
of Norwich and London, which firm have before this kindly allowed their wire to be freely used for experimental purposes. This wire stretches from Messrs. Colman's works at Norwich to their office in Cannon Street, a distance of a little over I 5 miles. The wire runs on the same poles as the numerous other wires of the Great Eastern Railway, and is carried overhead from the terminus in London to Cannon Street. At 4 o'clock the experiments began, and the incessant crackling and bubbling sounds in the receivers revealed the fact that the adjoining telegraph wires were at their busiest, and that induction could hardly be worse. Nevertheless, the first exclamation uttered into the bastily adjusted carbon telephone at Norwich was heard perfectly in the

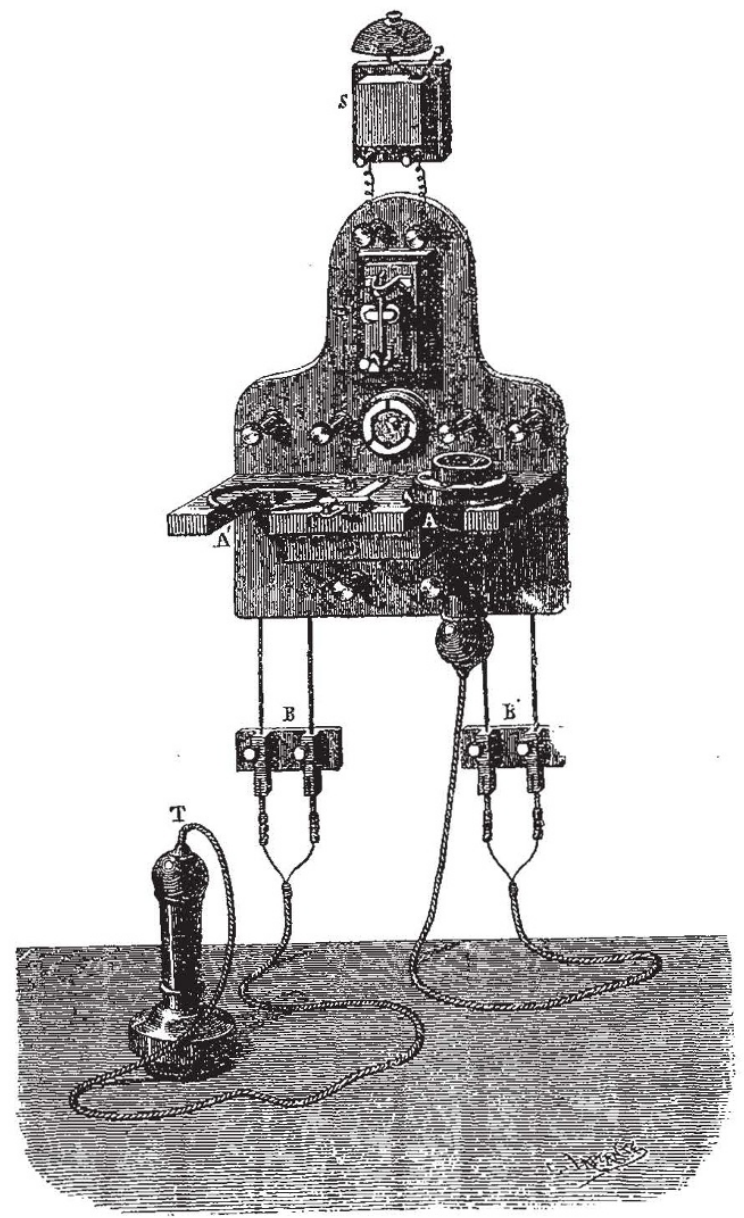

Fig. 4--Gereral view of the arrangements and accessories of the Carben Telephone.

counting-house at Cannon Street. Conversation then ensued between the two places; some words were occasionally lost, but the American accent of Mr. Adams, Mr. Edison's professional assistant, who had charge at the Norwich end, was distinctly recognisable in London. Remarks passed on the weather showed that a storm of snow and sleet was going on at both ends, and the insulation therefore almost at its worst. Later on, towards $90^{\prime}$ clock in the evening, the effects of induction grew less, but were still considerable. The voices from Norwich were now louder, the individuality of the speakers more marked, and conversation could be carried on without difficulty, the voices of certain speakers being remarkably distinct.

Twelve months previously the writer had an opportunity of trying Bell's tclephone on the same circuit, when not a word could be transmitted during the day, owing to induction, but at night everything was clearly heard; hence the foregoing experiments established the important fact that in spite of powerful induction operating against it, the Edison telephone is a practicable instrument. It is true that before this telephone can be commercially used, especially during the day and on long lines, special electrical adjustments of the instruments must be made such as the pressure on the carbon and probably the resistance of the induction coil relatively to the line, but in this there is no inherent difficulty, and the adjustment once made no further change is likely to be necessary. Meanwhile we shall await with curiosity the new receiver, which, in a recent letter to the writer, Edison says will arrive in England soon; they differ from other telephones in having "no ear pieces or magnets about them," and according to Edison, "are about twenty times louder than any magnetic telephone, and can, if desired, reproduce the voice at the distant end louder than originally spoken, whilst the whole affair is even cheaper and simpler than the receivers now in use."

It is not impossible that before very long, by means of the Edison telephone, speeches in Parliament may be telephonically transmitted to the newspaper offices and to the country, whilst honourable members, if their articulation be distinct, are speaking from their ordinary places in the House.

W. F. BARRETT

\section{NOTES}

THE Corporation of Penzance are, we hear, making preparations to celebrate the centenary of Sir Humphry Davy's birth next month. The Paris Academy of Sciences, who awarded Davy a prize in 1807 , when war was raging between France and Eugland, will probably take some part in the celebration.

A committee has been formed at Heilbronn with the object of erecting a monument to the memory of Dr. Robert Julius. Mayer in his native place. Every one knows that Dr. Mayer's name is associated with the establishment of the mechanical equivalent of heat (see NATURE, vol. xvii. p. 450).

THE Observatory of Geneva has received the gift of an instrument of large dimensions by the generous munificence of its director. Prof. Emil Plantamour, who has occupied this position for about forty years, has constructed, at his own expense, in the existing building, a turret of 7 metres in diameter, surmounted by a cylindrical cupola, in which will be placed an equatorial telescope of ro French inches aperture and $3.70 \mathrm{~m}$. focal distance. The object-glass has been ordered from Merz, of Munich, and the equatorial mounting is being manufactured at the workshop of the Geneva Society for the Construction of Physical Instruments. It is hoped that the new instrument will be in working order about the end of next spring.

Dr. Creighton, Demonstrator of Anatomy at Cambriclge, has joined the editorial council of the Journal of Anatomy and Physiology, which henceforth adds to its title the words "normal and pathological."

WE would call the attention of our readers to a paper, likely to be of some interest, to be read at the meeting of the Physical. Society on Saturday, by Messrs. Ayrton and Perry. The title of the paper is "The Music of Colour and of Visible Motion," and from what we can learn of Messrs. Ayrton and Perry's investigations, they claim to have hit on a new emotional art. BY means of a new machine which they have devised they can produce combinations of harmonic motions with greater variety than can be obtained with any existing machine. Their idea, we believe, is that, judging from their experience partly of the feelings produced by large bodies in rapid motion and rartly from the fact that in Japan posturing takes the place of the operatic 